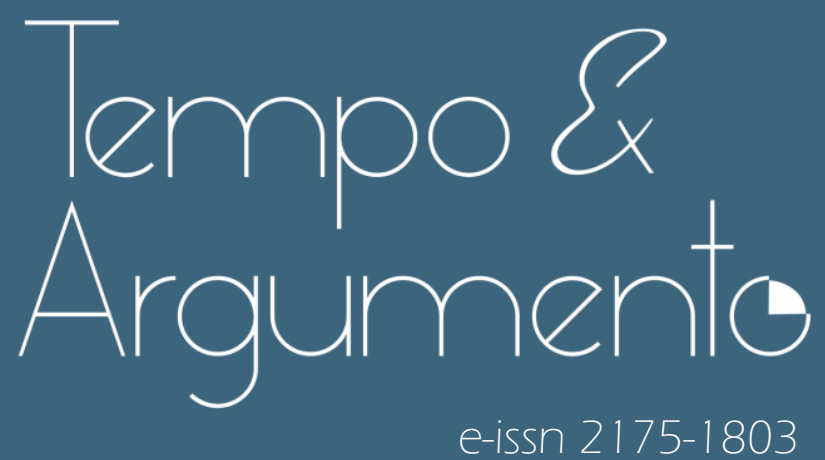

\title{
Patrimonio e identidad: la enseñanza de la historia ante el cambio social
}

\section{- Ana Isabel Ponce Gea}

Doctora en Educación por la Universidad de Murcia (España) y Doctora en Historia por la Universidade do Porto (Portugal). Profesora en la Universidad de Alicante,

Departamento de Didáctica General y Didácticas Específicas, Área de Teoría e historia de la Educación.

Alicante - ESPAÑA

cvnet.cpd.ua.es/curriculum-breve/es/ponce-gea-ana-isabel/373695

anaisabel.ponce@ua.es

(iD) orcid.org/0000-0003-0432-2595

5. Francisca José Serrano Pastor

Doctora en Filosofía y Ciencias de la Educación por la Universidad de Murcia (España).

Profesora en la Universidad de Murcia, Departamento de Métodos de Investigación y

Diagnóstico en Educación.

Murcia - ESPAÑA

um.es/web/depmide/contenido/departamento

fjserran@um.es

(D) orcid.org/0000-0002-5193-209X

Para citar este articulo (ABNT):

PONCE GEA, Ana Isabel; SERRANO PASTOR, Francisca José. Patrimonio e identidaı la enseñanza de la historia ante el cambio social. Tempo e Argumento,

Florianópolis, v. 13, n. 32, e0208, jan./abr. 2021.

doi http://dx.doi.org/10.5965/2175180313322021e0208

Recebido: 15/07/2020

Aprovado: 04/02/2021 


\title{
Patrimonio e identidad: la enseñanza de la historia ante el cambio social
}

\begin{abstract}
Resumen
Hacer de la historia un instrumento útil para nuestros estudiantes es una de las principales finalidades de los docentes, que necesitan definir un marco general en el que actuar de acuerdo con unos objetivos, cuya delimitación es especialmente imprescindible en momentos de cambio social. Este marco se conforma por dos planos principales: el cognitivo, donde se define el proceso de enseñanza-aprendizaje de la historia; y el social, donde lo realizado en la escuela se traduce en la utilidad para el educando, frecuentemente asociada a la conformación de una identidad. Entre ambos planos, el papel del patrimonio actúa como vertebrador, bajo dos argumentos principales: 1) El patrimonio puede ser tratado como una fuente histórica, que permite crear discursos múltiples a través de habilidades de pensamiento científico, crítico y creativo; 2) Como la historia, el patrimonio resulta esencial para la creación de la identidad y la formación de ciudadanos. Con esto en mente, se proponen tres posibles marcos en los que la utilidad de la historia depende de su tratamiento en las escuelas: a) identidad colectiva de consumo/patrimonio-objeto/conocimiento histórico insolvente; b) identidad colectiva dura/patrimonio-conmemoración/historia única y c) identidad colectiva débil/patrimonio-recurso/historia múltiple. Partiendo de que el cambio social, y el consiguiente cambio educativo, ha provocado una situación de identidades colectivas de consumo con consecuencias no deseadas, mostramos dos situaciones alternativas para la enseñanza de la historia. Ambas son útiles para el proceso educativo, dependiendo de qué entendamos por historia y en qué centremos su utilidad.
\end{abstract}

Palabras clave: Patrimonio. Enseñanza de la Historia. Identidad. Cambio Social.

\section{Heritage and Identity: to Teach History with the Social Change}

\begin{abstract}
Making history useful for students is one way of defining the main goal of teachers who need a general framework to act. To define the objectives is particularly important in the context of social changes. This general framework must be based on two levels: the cognitive, where teaching-learning of history is defined, and the social, where the consequences of the former, used at schools, influences the sense of usefulness. Between both, the role of heritage is pivotal. The rationale of the approach proposed in this paper can be explained through two main arguments: 1) Historical discipline is a scientific knowledge, although it is usually associated more to memorize than to reflect. In that sense, heritage can be treated as a historical source. Students can create multiple discourses if they have competences related to scientific, critical and creative thinking; 2 ) As history, heritage is a cornerstone in developing a sense of identity and should be used as such in schools to form citizens. With this in mind, three driving vectors are proposed where the usefulness of history depends on its treatment in schools: a) consumer collective identity/heritage-object/ insolvent historical knowledge; b) hard collective identity/heritage-commemoration/single history; and c) weak collective identity/heritageresource/multiple history. The paper is concerned with the different possibilities adopted by teachers, considering that the current situation corresponds to the consumer collective identity and analyzing its consequences. Responding to this, we show two coherent alternatives to history teaching. Both are useful to education process, depending on our comprehension of what history is and what its usefulness means.
\end{abstract}

Keywords: Heritage. History Teaching. Identity. Social Change. 


\section{UNA PRIMERA REFLEXIÓN: ¿QUÉ ES LA HISTORIA ÚTIL?}

La adjetivación de la historia escolar o la educación histórica como útil podría entenderse como el objetivo ideal que habríamos de compartir docentes e investigadores del campo de la didáctica de la historia. Su consecución supondría que el alumnado de nuestras aulas comprendiese por qué aprende historia y que ese mismo alumnado supiese también para qué lo hace.

La historia para el siglo XX, por arte de magia, no presenta una utilidad para el siglo XXI. La utilidad de la historia ha de entenderse desde su contextualización en el espacio y el tiempo; un espacio que, por la propia construcción de la disciplina y la posición de los autores, corresponde en este trabajo al mundo occidental, y un tiempo que, de definirlo de forma sintética, podríamos adjetivarlo como tiempo de cambio.

Así pues, más allá de las particularidades propias de la demarcación geográfica específica donde las prácticas educativas tengan lugar, las reflexiones sobre la educación han de realizarse en el marco del mundo global, de las políticas migratorias, de la individualización, de la digitalización y sus implicaciones para la configuración de las comunidades, de las modificaciones en las estructuras sociales y los cambios en la conceptualización del poder y de la exclusión social, de la heterogeneidad; en resumen, de las transformaciones continuas que hacen de cualquier innovación algo casi inmediatamente obsoleto.

La educación ha respondido y responde a estas transformaciones sociales. La Agenda 2030 marca como uno de sus Objetivos de Desarrollo Sostenible una educación de calidad, relacionándola con la educación inclusiva, equitativa y el aprendizaje para toda la vida. Además, el aprendizaje por competencias se encuentra integrado en la mayor parte de las legislaciones, atendiendo también las prácticas escolares a la resolución de problemas, la construcción crítica del conocimiento o el trabajo colaborativo como necesidades de la educación de este siglo. La educación emprendedora, personalista, la inclusión de la educación emocional y en valores, y la progresiva incorporación de las posibilidades de lo virtual también ponen de manifiesto la respuesta que el ámbito educativo articula en relación con los cambios descritos.

Sin embargo, estas transformaciones a nivel general no eximen de la reflexión para cada una de las didácticas aplicadas, que han de proponer e 
implementar en las aulas los cambios precisos para ser útiles a las sociedades actuales. Qué historia enseñar para este -ya no tan nuevo- siglo es un interrogante en el que nos encontramos desde hace décadas, estudiando esta cuestión frecuentemente fragmentada por la complejidad que presenta. Nuestra reflexión sobre la utilidad de la historia intenta crear un marco para la historia escolar que enlace algunos de los planteamientos más analizados de mano de la didáctica de la historia y la teoría de la educación; partiendo, para ello, de dos ideas que consideramos fundamentales. En primer lugar, la necesaria consideración de los principios epistemológicos de la historia como ciencia, imprescindibles para la reflexión sobre el modelo de enseñanza de la disciplina (el cómo) y la finalidad del mismo (el para qué). En torno a esta cuestión, entra en juego la ambivalencia existente para el significante historia, con una primera definición en relación con la disciplina histórica, que implica cómo sabemos lo que ocurrió en el pasado, cómo ha llegado a nosotros y desde dónde; y una segunda, como el conjunto de los acontecimientos ocurridos en el pasado. En otras palabras, el contraste entre la historia y el pasado, dos elementos indisociables pero no coincidentes (JENKINS, 2008; LOWENTHAL, 1998) resulta imprescindible. En segundo lugar, y partiendo de los mencionados planteamientos epistemológicos, consideramos la aportación que el patrimonio puede ofrecer a la enseñanza de la historia. Por un lado, el patrimonio históricocultural es una conexión entre el presente y el pasado, un vestigio aprehensible que tenemos de lo que fue, lo que implica poder ser utilizado como un recurso didáctico en los procesos de enseñanza-aprendizaje. Por otro lado, la propia definición del elemento patrimonial envuelve necesariamente una relación emocional y subjetiva, conectándose con una de las finalidades indiscutibles de la historia: la creación de una identidad. Así, pues, lo que algunos autores denominan como una educación patrimonial transcompleja (RODRíGUEZ, 2019) aboca a la reflexión sobre cómo utilizar el patrimonio (plano cognitivo) para conformar una identidad colectiva de la mano de la formación de la ciudadanía (plano social).

En este contexto de consideración de los principios epistemológicos de la disciplina y del patrimonio histórico-cultural como un recurso sobre el que son frecuentes las innovaciones e investigaciones, es donde cobra el sentido volver a 
la idea de utilidad para la enseñanza de la historia, partiendo de la creación de las identidades colectivas como una de sus principales finalidades. ¿Qué identidad colectiva crear en un mundo condenado a los cambios? ¿Cómo educar ciudadanos en un contexto de culturas modernas donde ha desaparecido el sentido de pertenencia a los referentes tradicionales (por ejemplo, la iglesia) y tiene lugar un profundo cambio en la construcción de la colectividad (ORGANIZACIÓN PARA LA COOPERACIÓN Y EL DESARROLLO ECONÓMICO (OCDE), 2019)? ¿Qué ciudadanos formar para los nuevos espacios públicos que generan las Tecnologías de la Información y la Comunicación (TIC) donde, con una facilidad nunca antes vista, cualquiera puede expresar su opinión? ¿Cómo educar y qué puede aportar la historia en un panorama de innovación continua que contrasta, sin embargo, con nuestro convencimiento de que no hay nada nuevo bajo el sol (INNERARITY, 2013)? ¿Qué tipo de identidades son susceptibles de luchar contra el individualismo, o ser compatibles con este? ¿O, acaso, ha de considerarse el propio individualismo como un rasgo propio de la identidad del grupo?

En este trabajo partimos de la premisa de que la formación de identidad por parte de la historia es tanto ineludible como hasta deseable, pues necesitamos de una identidad que, de no tener base en la historia, buscará otras alternativas. Los cambios en la materia de historia han intentado responder a las modificaciones continuas del contexto, caracterizado por el intercambio de ideas y de personas, por el aumento de la diversidad y por la caducidad de cualquier patrón. Sin embargo, esta cuestión se ha traducido frecuentemente en una materia vaciada de contenidos, como huida de su tradicional desempeño de creadora de la conciencia nacional, que ha dejado en manos de criterios intuitivos la formación de la identidad colectiva.

Es obvio que, al hablar de una historia escolar útil, asumimos una finalidad de la historia escolar condenada al debate según las ideologías y las tradiciones curriculares, y también que partimos de un ideal de identidad colectiva para las actuales sociedades democráticas y culturalmente diversas del siglo XXI, que no deja de ser una propuesta fundamentada. Ahora bien, el origen de este trabajo parte de la constatación de la pérdida del papel de la historia como creadora de 
identidad en nuestras escuelas, ofreciendo ante esta situación dos alternativas que hacen de la historia escolar un instrumento útil para unos u otros propósitos.

En resumen, partiendo del marco actual, describimos dos marcos alternativos para la enseñanza de la historia útil, considerando un determinado tipo de identidad colectiva que formar, qué perspectiva patrimonial actúa acorde con el objetivo identitario establecido y cómo se traduce en la metodología del proceso de enseñanza.

Antes de comenzar, definiremos la relación entre los elementos del marco, entre los que actúa el patrimonio como bisagra.

\section{LA CONFIGURACIÓN DEL MARCO: EL PATRIMONIO ENTRE EL PLANO COGNITIVO Y EL PLANO SOCIAL}

La propia naturaleza del elemento patrimonial hace que el término haya sido definido desde distintas disciplinas que lo han tenido como objeto de estudio. La antropología, la historia, la museología o la didáctica de las ciencias sociales han ofrecido definiciones en relación con sus contextos, conocimientos e incluso intereses; realizando aportaciones que no han presentado, seguramente, la suficiente interdisciplinariedad para que los niveles deseados de estudio y defensa patrimonial se conviertan en una realidad (MARTíN; CUENCA, 2015; MOLINA, 2017).

Sin embargo, lo que sí parece claro, independientemente de la procedencia del discurso, es que el concepto de patrimonio implica siempre una forma de conocimiento que une a un sujeto y a un objeto. Ese sujeto (individual o colectivo) construye, desde un contexto histórico y social, una representación, buscando simbolizar en el objeto (material o inmaterial) unos elementos que definan y cohesionen al grupo; por lo tanto, enfocándose desde el inicio hacia un plano social. Estos significados hacen de la representación una construcción y una expresión del sujeto (JODELET, 2000), que se modifica a lo largo del tiempo otorgando un significado diferente al patrimonio (MACDONALD, 2003). En otras palabras, la propia delimitación de lo patrimonial conlleva una dimensión conceptual y una dimensión emocional que se relacionan desde su inicio con los planos cognitivo y social de la historia, respectivamente. 
En este sentido, la perspectiva patrimonial adoptada dependerá y contribuirá, en una relación de doble sentido, a la identidad colectiva que se decida formar en nuestras escuelas, con una metodología didáctica acorde con los propósitos identitarios y el rol jugado por el elemento patrimonial. Estas perspectivas sobre el patrimonio -que abordaremos de forma más explícita en la categorización posterior y, en gran medida, de acuerdo con los planteamientos de Martín y Cuenca (2015) - pueden entenderse desde un análisis del campo semántico compartido entre patrimonio y herencia. Así pues, la herencia ha de interpretarse desde dos enfoques complementarios (GONZÁLEZ, 2006) que, en el terreno de la enseñanza, tienen sus repercusiones: herencia, como aquello heredado -el patrimoine francés, que pone énfasis en los antecesores; y, por lo tanto, en el pasado- y herencia, como aquello a dejar en herencia -el heritage inglés, con miras a los sucesores y, por lo tanto, al futuro-. De esta forma, la configuración del marco para la historia escolar, y la descripción de las diferentes opciones, permitirá la apuesta por una educación más retrospectiva o prospectiva (KOZULIN, 1998 apud SUBERO; ESTEBAN-GUITART, 2020) según la perspectiva patrimonial y los fines en el plano social.

Antes de describir las tres opciones categorizadoras que distinguimos para nuestro marco, entendemos la necesidad de realizar unas últimas aclaraciones en la relación del patrimonio con cada uno de los planos a los que venimos haciendo mención.

La relación existente en el plano cognitivo radica en el hecho de que el patrimonio se utiliza y se interpreta desde la enseñanza, uno de los principales canales de difusión del elemento patrimonial. Tanto es así que, en las últimas décadas, la educación patrimonial ha ofrecido numerosas perspectivas en la inclusión del patrimonio en los contextos educativos, llegándose incluso a considerar a la educación patrimonial como un campo de estudio propio y distinto de la didáctica de las ciencias sociales (CALAF, 2009). Este planteamiento no debe interpretarse, de ningún modo, como una ruptura en su relación con la enseñanza-aprendizaje de la historia, sino que ha de tomarse como base para un cambio de perspectiva, perspectiva en la que el papel que desempeña el sujeto que se relaciona con el patrimonio es esencial para su propia definición (GÓMEZREDONDO; FONTAL; IBÁÑEZ-ETXEBARRIA, 2016). Ahora bien, no podemos obviar 
que estos sujetos cuentan con un importante bagaje proveniente de los ámbitos familiares o de las "tecnologías de la memoria", como libros, películas, documentales, músicas... (CONWAY, 2003), que condiciona el mensaje escolar, llegando incluso a reducir a la mínima expresión su impacto sobre el alumnado (EPSTEIN, 2007). Lo anterior, que podría resultar una variable distorsionadora de nuestros posibles propósitos, abre, sin embargo, la puerta a la justificación de una perspectiva crítica y útil para la generación del conocimiento, aplicable al patrimonio proveniente de dentro y fuera de las aulas.

Se produce, entonces, una conexión directa con el plano social de la enseñanza de la historia. Entre las aportaciones que la historia pueda ofrecer a la educación, muy en relación con la evolución historiográfica de la disciplina madre, la creación de ciudadanos siempre ha sido una prioridad. De hecho, el Consejo de Europa (2018), al hablar de una educación histórica de calidad, lo asocia a la definición de las competencias para una cultura democrática. En esta línea, tanto el patrimonio como la historia apelan a la construcción de una identidad colectiva que no existe en abstracto, sino que se construye en contextos histórico-sociales e institucionales específicos (PÉREZ GARZÓN, 2016; SCHUGURENSKY, 2016) y utilizando unos determinados símbolos. El patrimonio, como ya señalábamos, no se limita a ser un vestigio del pasado, sino que su preservación viene argumentada desde su poder representativo. Tanto es así que la educación patrimonial es vista como una de las fuentes de la ciudadanía, entendida como sentimiento (identidad), como estatus (conservación) y como práctica (gestión) (LUCAS; DELGADO-ALGARRA, 2019). Precisamente, VanSledright (2008) habla de la enseñanza de la historia como patrimonio (history education as heritage and collective memory) para referirse a la historia escolar como construcción política, como contenidos seleccionados con una fuerte carga ideológica en el discurso y excluyente en tanto que, con frecuencia, no asume la pluralidad de perspectivas, sino que se formula desde la unidimensionalidad (RIEFF, 2012; PÉREZ GARZÓN, 2016).

En relación con lo expuesto en ambos planos, dos ideas resultan esenciales. La primera es ser conscientes de que la elección del patrimonio nunca es fortuita, ni a nivel curricular ni a nivel de aula. A este respecto, cuando en el desarrollo curricular se incluyen o excluyen determinados elementos 
patrimoniales o cuando se priman unos respecto a otros, se está configurando una imagen de la historia y de la sociedad, que influirá en la construcción de la identidad. Indudablemente, existe un sesgo en la elección del patrimonio que reviste un interés político. La segunda es que todos los elementos patrimoniales son fuentes históricas en tanto en cuanto de ellos puede extraerse información de otros tiempos. Consecuentemente, el trabajo con el patrimonio en nuestras aulas ha de abarcar las distintas tipologías patrimoniales (histórico-artístico, natural, oral, industrial...).

A partir de las relaciones explicadas, esquematizamos en el gráfico 1 los tres grandes planteamientos a partir de los cuales pueden entenderse el sentido de la enseñanza de la historia y su utilidad. De este modo, los conjuntos identidad colectiva de consumo/patrimonio-objeto/conocimiento histórico insolvente, identidad colectiva dura/patrimonio-conmemoración/historia única e identidad colectiva blanda/patrimonio-recurso/historia múltiple representan tres perspectivas coherentes para la didáctica de la historia donde los dos planos y la perspectiva patrimonial quedan perfectamente relacionados, del modo en el que habrían de estarlo en nuestros planteamientos de enseñanza, cualquiera que sea nuestra elección según los objetivos marcados.

Gráfico 1 - El patrimonio como eje vertebrador entre el plano cognitivo y el plano social

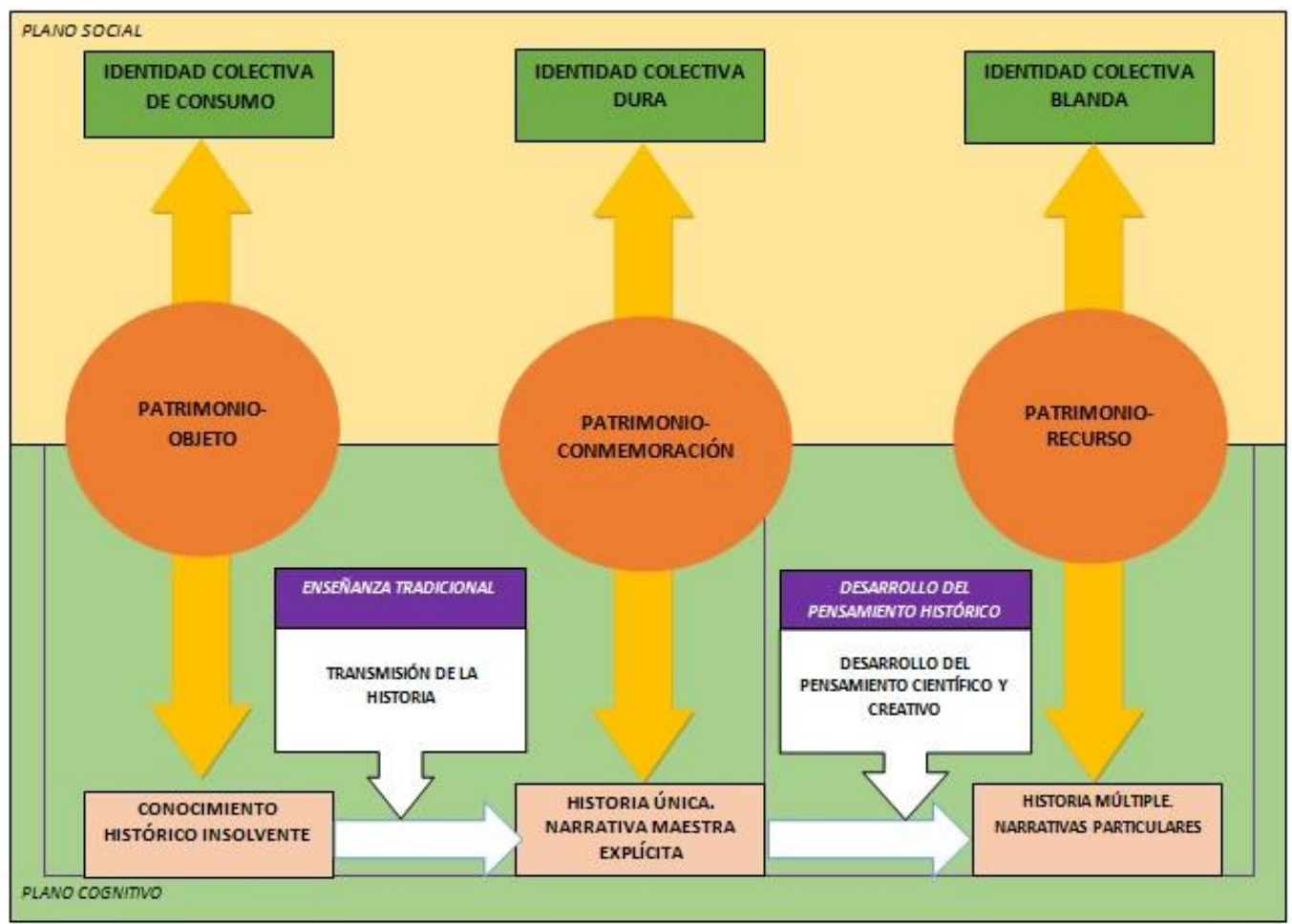

Fuente: elaboración propia, 2019. 
En lo siguiente, comentaremos cada uno de estos posibles marcos, comenzando por la situación de conocimiento histórico insolvente (que creemos que se acerca más a la situación actual), para describir después los dos marcos restantes como alternativas a una conformación de la identidad colectiva ajena a la historia.

\subsection{El patrimonio-objeto}

La memoria colectiva, esencial para la definición del patrimonio (PINTO, 2016), ha ido rescatando imágenes, a modo de símbolos, que representan a la colectividad. Cuando estos símbolos son elementos patrimoniales, se relacionan, muy a menudo, con sentimientos identitarios en el modo al que hacíamos referencia al explicar las relaciones internas a nuestro marco.

Sin embargo, en ocasiones, una colectividad apoya su idea de grupo en elementos no argumentados histórica o culturalmente. Es decir, existe un grupo que se define como tal porque comparte ciertos elementos no apoyados en razones históricas, y en los que la idea de memoria colectiva también es muy débil, puesto que ni siquiera articula un mensaje coherente y lógico que justifique un presente. Se trata de elementos acumulativos de un pasado sin aparente elemento organizador. $Y$ decimos aparente porque, y como insistiremos, de manera intencionada o no, termina por encontrar un eje vertebrador, muy propio de las sociedades modernas, que intenta conjugar a la vez un aumento de la individualidad al tiempo que mantener la pertenencia a unos esquemas de referencia tradicionales como es el estado-nación.

Desde esta perspectiva, en el mejor de los casos, podríamos hablar de que existe una identidad colectiva pero, de ningún modo, una identidad histórica, sino una identidad que llamaremos de consumo. La ausencia de dicha identidad histórica -basada en la no explícita presencia de un discurso histórico esencialista que la sustente- conlleva la búsqueda de elementos con los que el grupo se identifica a través de razones casi intuitivas. Estos elementos, que pueden ser de lo más variados -que de hecho, han sido en la historia de lo más variados-, en el caso de tratarse de elementos patrimoniales, convierten al patrimonio en un objeto, como otro cualquiera, sobre el que articular una identidad. 
Las características del uso del patrimonio en este sentido son aquellas que empiezan y acaban en razones intrínsecas al mismo elemento, acorde con la historia anticuaria de Nietzsche. Bajo la categoría de patrimonio-objeto se incluyen las perspectivas fetichista, estética, monumental, temporal y de diversidad de Martín y Cuenca (2015), siendo especialmente las tres primeras las que definen las razones principales en las que se sustenta la categoría: la escasez, la peculiaridad, la antigüedad o la belleza. En la misma línea, el patrimonio puede entenderse como tesoro, como memoria o incluso como cultura para su definición (GONZÁLEZ, 2006).

Estamos hablando del patrimonio como objeto cuando, por ejemplo, señalamos la Alhambra como símbolo de Granada, sin que en esa identificación el colectivo utilice argumentos históricos -o de memoria colectiva-, para justificar su presente en un discurso. El patrimonio -o el sujeto que con este se relaciona- no pretende legitimar explícitamente ningún presente -mucho menos futuro-, mostrándose simplemente como una ilustración que acompaña un discurso supuestamente objetivo que se limita a la descripción de hechos pasados. Su defensa como patrimonio se basa en valores estéticos y no morales. Carece de justificación o razón de ser un discurso teleológico, que facilita, por tanto, el debilitamiento de la identidad colectiva que pudiera suponer un freno al proceso de globalización. El patrimonio no tiene más valor que el que tendría, de hecho, el equipamiento de un determinado club de fútbol, con el mismo sentido también para la creación de la colectividad.

La relación del patrimonio-objeto con los planos cognitivo y social la representamos en el gráfico 2.

Gráfico 2 - Relación del patrimonio-objeto con los planos cognitivo y social

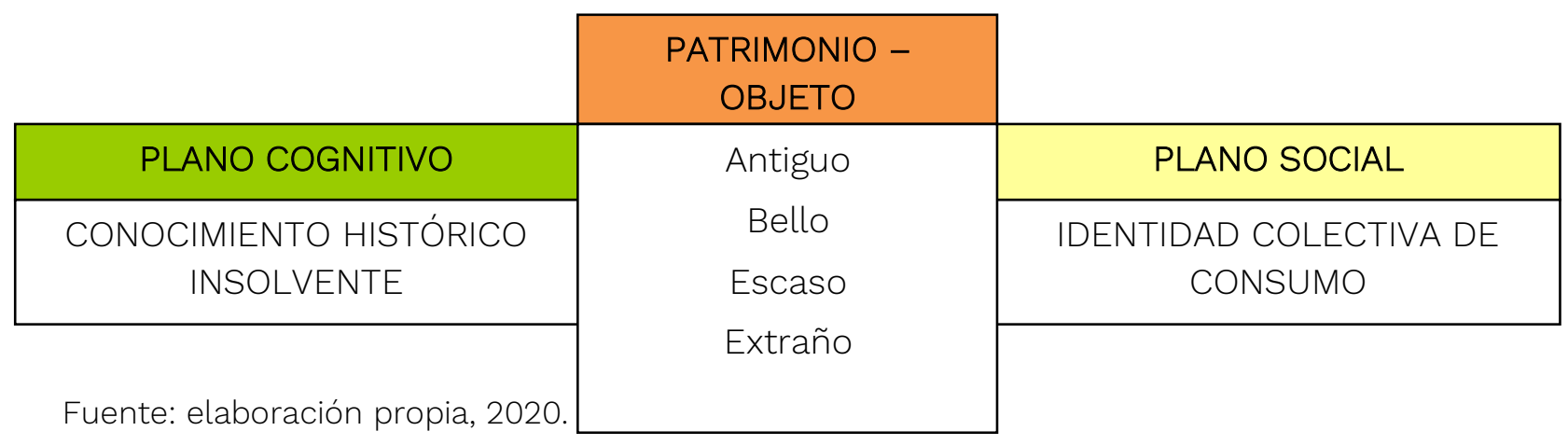


En el plano social, definir el patrimonio desde criterios intuitivos, bajo una perspectiva que podríamos resumir como estética, se traduce, como decíamos, en una identidad colectiva débil. Los rasgos de dicha identidad, que llamaremos de consumo, pueden encontrarse en la tabla 1.

Para el establecimiento de las distintas dimensiones, hemos adoptado como principal referencia los postulados que enuncia Rachik (2006) en su descripción de las identidades duras y blandas, sobre las cuales trataremos a partir de las dos restantes perspectivas sobre el patrimonio (patrimonioconmemoración y patrimonio-recurso).

Tabla 1 - Caracterización de la identidad colectiva de consumo

\begin{tabular}{|l|c|}
\hline \multicolumn{2}{|c|}{ IDENTIDAD COLECTIVA DE CONSUMO } \\
\hline UNIVOCIDAD & Múltiple \\
\hline NATURALEZA & Cambiante \\
\hline APRENDIZAJE & Consumida \\
\hline RELACIÓN CON EL INDIVIDUO & Selectiva \\
\hline ORIENTACIÓN & Homogeneizadora- Polarizadora \\
\hline FACTORES DE DEFINICIÓN & Intuitivos \\
\hline
\end{tabular}

Fuente: elaboración propia, 2020.

Entendemos la identidad colectiva de consumo como una identidad colectiva existente y múltiple, en tanto que muestra un pasado plagado de intercambios culturales para explicar una supuesta heterogeneidad en el presente. Al basarse en factores intuitivos para su definición, estamos hablando de subjetividades que originan identidades frente a identidad. Cada individuo entenderá la identidad desde su individualidad y desde su posible pertenencia a varios colectivos, pudiendo asumir las características básicas de esa identidad colectiva, pero renunciando a otros aspectos con los que no se identifica o no son de su agrado.

El final del siglo XX, con el desarrollo de los medios de masas, la sociedad de la información y el consumismo nos colocó en un escenario de continua itinerancia provocada por la ausencia de claras fronteras (físicas, culturales y económicas) que ha propiciado estas identidades de consumo. La identidad, que ahora se articula sobre bases postnacionales, transculturales o híbridas, por la 
complejidad a la que someten al individuo, parece ofrecer a este individuo una mayor capacidad y libertad de elegir los marcos de referencia. Sin embargo, el resultado de la supuesta libertad y elección del individuo da como resultado, en multitud de situaciones, comportamientos similares. Los motivos se encontrarían en una serie de apreciaciones relevantes. En primer lugar, las consecuencias y libertades propias de la globalización son dispares según la riqueza de los individuos (BAUMAN, 2003), de ahí su caracterización como homogeneizadorapolarizadora. Y, en segundo lugar, los marcos de referencia geográficos siguen imperando en los currículos de la educación formal, con su enorme peso e influencia (CISCAR; SANTIAGO; SOUTO, 2011).

Lo anterior acaba traduciéndose en un mundo individualizado donde se defiende el carácter competencial del individuo responsable de su suerte -con claro impacto en la idea de competencias educativas que impregnan numerosos currículos educativos en todo el mundo y auspiciados por la OCDE-, donde la idea de comunidad se ve debilitada y el estado del bienestar se cuestiona. ¿Cómo? La desunión entre historia y patrimonio en un discurso histórico sólido ayuda a debilitar la existencia de valores verdaderamente colectivos. La muestra de datos históricos y referencias monumentales a modo de catálogo en los libros de texto pueden contribuir a percibir la identidad como una elección. Sin embargo, el discurso histórico descontextualizado siempre termina con las bondades de la organización social, política y económica vigente donde prima la rentabilidad económica por encima de cualquier otro elemento -como podría ser, por ejemplo, la preservación etnológica- (SCHUGURENSKI, 2006; TAROZZI; TORRES, 2016).

La coexistencia de las tendencias globales con marcos tradicionales de referencia como el estado-nación provoca que se busquen unos mínimos elementos referenciales que, descontextualizados históricamente, hacen que el patrimonio presente exclusivamente fines lúdicos y económicos -mensaje repetido constantemente por medios de comunicación, videojuegos...- y con un uso puramente consumidor - sin participación en la identificación de la relevancia de tal objeto como hemos apuntado desde el punto de vista cognitivo-. El patrimonio se convierte así en un objeto de consumo, ya sea lúdico o estético 
(PINTO, 2016), al que, en muchos casos, se accede por su carácter de fama pública, y en el que la relación del individuo con él se limita en multitud de situaciones a servir de escenario para la autodifusión en las redes sociales.

Así entendido, el patrimonio no necesita, en el plano cognitivo, de un discurso histórico que lo sustente, pues se selecciona de acuerdo con otros criterios, intuitivos. Puede existir un conocimiento histórico pero, en todo caso, este será insolvente, pues predominarán los contenidos de primer orden, descontextualizados, que no permitirán una explicación de la historia ni de las razones de causalidad.

Ese conocimiento puntual puede confundirse, en ocasiones, con un argumento histórico, en tanto en cuanto algo puede conservarse justificado por ser antiguo. Sin embargo, el conocimiento de una fecha, de un contenido descontextualizado, es insuficiente para dicha argumentación. Estaríamos hablando, utilizando un símil económico, de una participación totalmente pasiva, donde se privilegia el consumo de un producto -cultural- por encima del proceso de producción del mismo -es decir, no se participa de forma activa en la generación del sentimiento de relevancia del producto para el consumidor-. Un consumo de algo de lo que no somos partícipes, y donde ese valor de intercambio, según VanSledright (2008), es gestionado, dirigido por terceros que requieren, juzgan y sancionan la reproducción, no al reproductor en sí mismo. Desde esta perspectiva, las habilidades que demuestra el discente no pasarían del primer escalón de la taxonomía de Bloom, pues ni tan siquiera podríamos estar hablando de una comprensión del fenómeno, mucho menos de una evaluación.

En las concepciones de los docentes y los libros de texto españoles la definición del patrimonio bajo los criterios arriba mencionados (escasez, belleza...) es frecuente (CUENCA-LÓPEZ; ESTEPA-GIMÉNEZ; MARTÍN, 2017), limitando el uso del patrimonio a fines meramente ilustrativos, que reducen el pasado a mundos de fantasía que se consumen para evadirse de la realidad presente. Así, escolarización y cultura de consumo de masas parecen encontrarse en un apoyo mutuo, tal vez incluso simbiótico, en una danza socioeconómica (VANSLEDRIGHT, 2008). 
La necesidad de alejarnos del discurso cerrado (tradicionalmente, patriótico) ante la diversidad social; la renovación pedagógica de las escuelas que, en lugar de acercarse a métodos como el trabajo por proyectos que faciliten la crítica y construcción de los discursos, se ha traducido en un vaciado curricular-; y la tendencia al individualismo sin renunciar a los referentes tradicionales -que se presentan como salvadores del primero desde marcos que no siempre son compatibles con los tiempos- hacen de la historia escolar un instrumento poco útil para la construcción de identidades colectivas. Sin embargo, estas identidades han de construirse de algún modo; de forma que, si no son reguladas por los individuos críticos de la sociedad, vendrán dadas y consumidas.

\subsection{El patrimonio-conmemoración}

El uso de lo que denominaremos patrimonio-conmemoración y su relación con la historia tienen un rancio abolengo. La existencia de museos públicos donde conservar y exponer el patrimonio histórico-artístico, el desarrollo de los estados-nación, la aparición del concepto de ciudadanía y la consideración de la historia como un saber científico encuentran su origen a finales del siglo XVIII (MACDONALD, 2003). La necesidad de culturizar al pueblo y de que esa cultura sirviese para generar un sentimiento de unión entre individuos que no tenían más relación entre ellos que la de pertenencia a un estado, a la par que se fomentaban unos lazos de fidelidad entre esos ciudadanos, contó con un aliado poderoso en la enseñanza de la historia y en la búsqueda de símbolos. Los nuevos poderes establecidos usaron la conjunción de la historia -entendida como una memoria colectiva y no un saber científico- y el potencial de los museos/patrimonio para justificar los valores que las nuevas relaciones de poder demandaban (MACMILLAN, 2010). En este sentido, la aparición de aniversarios, conmemoraciones y la publicación de historias nacionales se apropiaban de los espacios públicos de la ciudadanía, convirtiéndose estos en lugares de enseñanza, pero también de adoctrinamiento. Esta conexión entre historia, estado-nación e identidades colectivas tuvo, ha tenido y aún tiene en el libro de texto un instrumento decisivo, ya que su papel no era en su momento -y todavía no es en muchos casos- el de enseñar historia, sino el de generar una memoria 
colectiva en la que el debate y el proceso de crítica estaban -y están muy a menudo- ausentes (CARRETERO, 2007). Incluso en manuales realizados por historiadores, los elementos propios de la historia como son el debate, la duda y la fundamentación del discurso se eliminan por certezas y mensajes cerrados cuando van dirigidos a niños y a agentes externos a la sociedad definida para conseguir así su correcta socialización (VANSLEDRIGHT, 2008).

Las grandes narrativas maestras de los libros de texto y de las crónicas locales - donde se incluyen los elementos patrimoniales - se refieren a individuos o colectivos cuyos valores y hechos extraordinarios deben ser celebrados y emulados, por lo que la preservación del patrimonio se vincula con tales actitudes y concepción de la colectividad -habitualmente identificada con el estado-nación- que debe proyectarse en una duración indefinida (GATTI, 2007).

En este contexto de creación de una identidad objetiva y compartida, el patrimonio-conmemoración puede ser singular, bello o antiguo pero sus factores de definición radican en ser, principalmente, simbólico y nuestro. Asumimos una perspectiva simbólico-identitaria (MARTíN; CUENCA, 2015), compatible con la historia monumental de Nietzsche, en la que el patrimonio habría de ser conservado para los que vienen después. El patrimonio es simbólico, porque representa; es emotivo, porque son las emociones las que dan sentido a la relación sujeto-objeto que comentábamos al inicio; es nuestro, porque sentimos que nos pertenece; y es territorial, porque esa pertenencia la definimos de acuerdo con un espacio físico, pese a su abstracción. En esencia, el patrimonio se asocia a una escala espacial (local, regional, nacional) siendo un elemento a través del cual nos identificamos.

Sin duda alguna, el paso del patrimonio-objeto al patrimonioconmemoración hace que ya no sea suficiente con identificar o definir, sino que necesitamos comprender, analizar o sintetizar, si bien dentro de los parámetros del discurso cerrado que lo mantiene. De hecho, ciertos cambios llevados a cabo en currículos educativos en los que la enseñanza de la materia de historia se orientaba hacia discursos más críticos e interpretativos han levantado airadas protestas por descuidar lo que se ha considerado tradicionalmente el papel de la materia (y del patrimonio) como elemento ejemplificador de tales valores, dando pie a las llamadas history wars, que se traducen en qué papel ha de jugar 
la historia en relación con los sentimientos de los individuos respecto a su pertenencia a una colectividad (HUTCHINS, 2015).

Por lo tanto, el patrimonio, entendido desde esta perspectiva, necesita de un discurso histórico que lo sostenga desde la enseñanza -único y sin contradicciones- y se destina hacia una identidad colectiva dura, fija y compartida, en la que se reconoce cada individuo de la sociedad (Gráfico 3).

Gráfico 3 - Relación del patrimonio-conmemoración con los planos cognitivo y social

\begin{tabular}{|c|c|c|}
\multicolumn{1}{c|}{} & $\begin{array}{c}\text { PATRIMONIO - } \\
\text { CONMEMORACIÓN }\end{array}$ & \multicolumn{1}{c|}{ PLANO SOCIAL } \\
\hline PLANO COGNITIVO & Simbólico & Emotivo \\
MISTORIA ÚNICA. NARRATIVA & Territorial & \\
Fuente: elaboración propia, 2020. & Nuestro & \\
& &
\end{tabular}

Cuando hablamos de una identidad colectiva dura (RACHIK, 2006) (Tabla 2) estamos hablando de una identidad fundamentada en uno o varios criterios considerados objetivos. Esos elementos culturales objetivos -lengua, religión, costumbres... - vienen dados por la narrativa maestra y aseguran una continuidad social. Habermas (1987 apud MERCADO; HERNÁNDEZ, 2010), en la que llamaba etapa simbólica para la integración de la identidad, hablaba de los valores, las imágenes, los mitos que actúan como elemento cohesionador y como marco normativo. La identidad dura es el resultado de la aplicación de un tipo de enseñanza de la historia -la transmisora- que difiere de la propia del patrimonioobjeto, si bien con elementos de coincidencia. A través del uso del patrimonioobjeto, el discurso histórico elaborado pretende enseñar a los ciudadanos que son libres dentro de un proyecto (más allá de que este tenga, como hemos visto, una dirección definida y un resultado previsto). Por el contrario, la identidad colectiva dura es el fruto de un discurso claro y explícito encaminado a que los valores del pasado tengan una clara proyección en las conductas futuras y no permite interpretaciones múltiples pues tiene la intención clara de definir a un grupo para oponerlo al otro (RACHIK, 2006). 
Este tipo de identidad, con elementos fijos y reticentes al cambio, es propia de sociedades que buscan la perdurabilidad, para lo que utilizan posturas más esencialistas (LÓPEZ; RODRÍGUEZ, 2014): esto es así porque no puede ser de otra forma; la historia solo ha sido una y no puede ser interpretada.

Tabla 2 - Caracterización de la identidad colectiva dura

\begin{tabular}{|l|c|}
\hline \multicolumn{2}{|c|}{ IDENTIDAD COLECTIVA DURA } \\
\hline UNIVOCIDAD & Única \\
\hline NATURALEZA & Fija \\
\hline APRENDIZAJE & Dada \\
\hline RELACIÓN CON EL INDIVIDUO & Autoritaria \\
\hline ORIENTACIÓN & Homogeneizadora-unificadora \\
\hline FACTORES DE DEFINICIÓN & Históricos-Objetivos \\
\hline
\end{tabular}

Fuente: Elaboración propia, 2020.

Lo cierto es que, aunque la mayoría de escolares ven las identidades colectivas como socialmente construidas, el hecho de que aquellos que sostienen esas identidades las ofrezcan como fijas y con el objetivo de homogeneizar hace que, finalmente, los individuos tengan un sentido, incluso biológico, de la identidad (JASPER; MCGARRY, 2015). Tanto es así que se puede pertenecer a una determinada identidad sin saberlo o en contra de uno mismo y que queda patente en la representación mental que uno tiene del mundo, y que de forma inconsciente aflora cuando es interrogado sobre la significatividad de elementos geográficos o históricos (MORALES; CAURÍN; SOUTO, 2013).

En el plano cognitivo, esta forma de entender el patrimonio se relaciona con la posesión de un discurso histórico que sirve para argumentarlo. Ahora bien, del mismo modo en el que la identidad es una y unos son los elementos patrimoniales que la representan, la historia también es una y es donde se incluye el patrimonio y se refuerza la identidad.

Los grands récits ofrecen una sola -y privilegiada- visión del pasado (ANGULO, 2010), una visión transmitida como verdad absoluta, donde los términos pasado e historia actúan como sinónimos: la historia es el pasado. Estas grandes narrativas, o narrativas maestras, pueden justificar la selección del 
patrimonio según el papel que juega en el discurso, según su relevancia histórica (SEIXAS; MORTON, 2013). Pero esa relevancia histórica de la cual no forman parte los destinatarios del discurso suele explicar una sola parte de los fenómenos más complejos, fomentando las generalizaciones e ignorando los hechos que no cuadran con tal discurso. La integración del patrimonio en la narrativa maestra puede tener una mayor o menor relevancia pero, de uno u otro modo, no dejará de ser un elemento complementario en un discurso que parece haberse construido por arte de magia pero que, finalmente, nos hace ser como somos.

En consecuencia, la apuesta por una identidad dura vendrá de la mano, en el terreno de la enseñanza, de una metodología tradicional, donde la relación profesor-alumno puede limitarse a la unidireccionalidad. La enseñanza transmisiva y el aprendizaje memorístico son técnicas suficientes para un discurso que el alumno ha de aprender, cargado de contenido conceptual, y ante el que no existen versiones alternativas. En resumen, la historia única en el plano cognitivo asegurará una identidad única en el plano social, interpretándose el patrimonio en este contexto: patrimonio es lo que nos representa y nos pertenece.

No podemos ni mucho menos pensar que el patrimonio-conmemorativo se encuentra en desuso. Son cada vez más los ejemplos que encontramos donde la vuelta a la unidad de referencia estado-nación (Reino Unido, Estados Unidos, Francia, Holanda...) o al intento de crear unidades nacionales nuevas (Quebec, Cataluña, Escocia...) están cobrando fuerza por medio de movimientos políticos nacionalistas en auge. Y estos ejemplos, en el corazón mismo del mundo capitalista global. En todos estos casos, en los ya existentes y en los que puedan existir, la justificación de una memoria colectiva común se encuentra en el epicentro de los discursos esencialistas y excluyentes (MACMILLAN, 2010).

\subsection{El patrimonio-recurso}

Nuestra definición de patrimonio-recurso puede aplicarse a aquel patrimonio que, además de poder poseer unas características estéticas, inusuales o representativas de un pueblo, es concebido por los individuos de una colectividad como un elemento útil. Esa utilidad puede tener relación con el 
ámbito económico - de hecho, es un elemento totalmente válido y dinamizador para una comunidad-, pero posee especial vinculación con el ámbito educativo, entendiendo el patrimonio como fuente histórica. Diríamos más, una rentabilidad del patrimonio que podríamos calificar como económica -por ejemplo, a nivel turístico- no asegura que su rol en cuanto a la construcción de la identidad no se limite, igualmente, a esa imagen consumida.

En el ámbito educativo, concebir el patrimonio como recurso se traduce en insertar al alumnado en la fase de producción o generación del conocimiento, y seguramente establecer un vínculo de significatividad entre patrimonio e individuo.

La utilidad del patrimonio en el terreno educativo ha sido defendida desde planteamientos que ven en la educación patrimonial una disciplina con suficiente independencia e identidad (FONTAL, 2003). Desde otras vertientes, se ha intentado una sistematización para la inclusión en el proceso de enseñanzaaprendizaje (CUENCA-LÓPEZ; ESTEPA-GIMÉNEZ; MARTÍN, 2017). Nuestra visión de utilidad radica en la concepción del patrimonio como fuente histórica (PINTO, 2013; SOLÉ, 2017; VAN BOXTEL, GREVER; KLEIN, 2015), a partir de la que construir discursos a través del método del historiador. Se trataría, por lo tanto, de historizar el patrimonio estudiando y comprendiendo el cambio social desde un momento histórico determinado hasta el presente, adoptando la postura dinámica de evolución -que no necesariamente progreso-social.

Esta perspectiva patrimonial como patrimonio-recurso permitirá la elaboración de narrativas particulares desde la enseñanza, lo que en el plano social estará enfocado hacia la construcción de una identidad colectiva blanda, múltiple y libre (Gráfico 4).

Gráfico 4 - Relación del patrimonio-recurso con los planos cognitivo y social

\begin{tabular}{|c|c|c|}
\multicolumn{1}{c|}{} & $\begin{array}{c}\text { PATRIMONIO - } \\
\text { RECURSO }\end{array}$ \\
\hline PLANO COGNITIVO & Útil & PLANO SOCIAL \\
HISTORIA MÚLTIPLE. & Informativo & BLENTIDAD COLECTIVA \\
Fuente: elaboración propia, 2020. & Rentable & \\
& &
\end{tabular}


Caracterizar al patrimonio como recurso supone el paso de una concepción en la que se prima el peso del pasado para el razonamiento sobre el presente a otra concepción donde la relación con el presente se prolonga con vistas hacia el futuro. En otros términos, conlleva la necesidad de la conciencia histórica frente a la memoria (RÜSEN, 2008), lo que tendrá como consecuencia la construcción de identidades colectivas blandas frente a las duras propias del patrimonio-conmemoración (RACHIK, 2006). En resumen, es usar la historia, no solo para saber quiénes somos o de dónde venimos, sino principalmente para conocer en qué podríamos convertirnos (LÓPEZ; RODRíGUEZ, 2014).

Una identidad colectiva blanda (Tabla 3), tal y como la conceptualizamos, necesita, pues, de una definición con base histórica que, sin embargo, será múltiple pues el discurso histórico dependerá en gran medida del individuo que pasa de consumidor a productor. La identidad blanda es precisamente el resultado del análisis crítico, de las múltiples perspectivas o multivocalidad que el hecho histórico y patrimonial proporcionan (BURKE, 1993).

Tabla 3 - Caracterización de la identidad colectiva dura

\begin{tabular}{|l|c|}
\hline \multicolumn{2}{|c|}{ IDENTIDAD COLECTIVA BLANDA } \\
\hline UNIVOCIDAD & Múltiple \\
\hline NATURALEZA & Cambiante \\
\hline APRENDIZAJE & Construida \\
\hline RELACIÓN CON EL INDIVIDUO & Libre \\
\hline ORIENTACIÓN & Diversificadora \\
\hline FACTORES DE DEFINICIÓN & Históricos-Subjetivos \\
\hline
\end{tabular}

Fuente: elaboración propia, 2020.

El debilitamiento de las estructuras establecidas durante siglos -sólidas o modernas- ha fomentado, como hemos visto ya, la individualización de la sociedad pero también, al desincrustar al individuo de dichas estructuras, le da la posibilidad, casi obligación, de hacer uso de nuevos estadios de identificación colectiva. Así, la primera fase en la integración de la identidad de Habermas (1987, apud MERCADO; HERNÁNDEZ, 2010), la fase simbólica, ha de sustituirse por la que llama el autor de integración comunicativa; esa donde la identidad, cada vez más abstracta y universal, se construye a partir de todas las realidades. 
En este contexto, el de la diferencia, el concepto de alteridad como capacidad de aceptar al otro (PINTO, 2013) cobra otro sentido. La enseñanza de la historia, desde el dinamismo, el cambio, la multivocalidad y la indagación, desde la disolución de la identificación de pasado con historia... rompe la visión esencialista o unidad de destino en lo universal de las comunidades identitarias y, por lo tanto, el carácter excluyente que pudieran aportar. Se trata, pues, de una enseñanza del pasado para una nueva sociedad del siglo XXI. Estamos hablando de formar una identidad que acoge, que cambia, y lo hace en el marco de las interpretaciones múltiples que los individuos realizan sobre las fuentes. Si las historias sobre el pasado son varias, es sencillo entonces entender la multiplicidad en la identidad: externa (cada uno de nosotros somos poseedores de múltiples identidades, pues pertenecemos a múltiples colectividades con las que nos identificamos) e interna (cada uno de nosotros puede elegir y renunciar a algunos aspectos de la identidad construida, lo que no implica quedar fuera de la colectividad).

En el plano cognitivo, esta perspectiva patrimonial no necesita ya de un discurso único y dado donde se incluya el patrimonio para argumentar la identidad, pues el patrimonio es la fuente que el sujeto habrá de interpretar para elaborar su propio discurso. Así pues, la identificación y el análisis del patrimonio habrán de completarse ahora con la evaluación de los elementos patrimoniales y de los discursos propios que porta cada uno de ellos, fruto de la concepción de patrimonio-conmemoración.

Lo anterior se traduce en el desarrollo de habilidades de pensamiento sobre el conocimiento histórico, en hacer partícipe al alumnado en la cognición de la historia. Es lo que llamamos trabajar el pensamiento histórico o adquirir una alfabetización histórica, lo que, en cualquier caso, conlleva que se pongan en funcionamiento los mismos conceptos y procedimientos seguidos por el historiador (ERCIKAN; SEIXAS, 2015; SEIXAS; MORTON, 2013). A grandes rasgos, hemos de lograr que los estudiantes sepan realizar preguntas adecuadas a las fuentes y evalúen su información, convirtiendo estas fuentes en evidencias, y que las evidencias sean corroboradas articulando un discurso histórico (VANSLEDRIGHT, 2014). Por lo tanto, se han de desarrollar en el alumno las 
habilidades de la historia entendida como ciencia, prestando especial atención también al pensamiento crítico y creativo (PONCE, 2019).

Desde esta perspectiva, el patrimonio como recurso educativo aporta un valor excepcional en la enseñanza de dicho pensamiento histórico, permitiendo que el alumnado pueda experimentar la aplicación de los conocimientos históricos en su vivencia cultural con el patrimonio inmediato (CROUCH, 2015). La clave se encuentra en que el uso de recursos patrimoniales no solo aporta información como fuente histórica, sino que permite entender y comprender el contexto particular y propio de la sociedad que genera dichos elementos patrimoniales, a través su unión emocional.

La doble visión del patrimonio como representación y como fuente permite la comprensión de la perspectiva histórica o sentido de empatía histórica (BARTON; LEVSTIK, 2004), al tiempo que permite analizar toda la construcción y génesis de la representación como hecho histórico -generación del concepto de historical significance o memory significance-. Esto no implica estar de acuerdo con los acontecimientos pasados sino apreciar las diferencias entre las cosmovisiones de las sociedades pasadas y actuales e intentar comprender la perspectiva de los agentes históricos mediante la comprensión de su contexto. Es decir, el patrimonio permite desarrollar el proceso de reconocimiento de las experiencias de otras personas de una manera efectiva y tangible, y rastrear el motivo de su identificación como patrimonio a través de la generación del discurso que marca su relevancia, en tanto que se considera la historia -la narración del pasado- como una versión de este (MARCUS; STODDARD; WATERTON; WATSON, 2015; WOODWARD, 2012).

Al ser el patrimonio considerado como fuente y escogido entre otros elementos susceptibles de ser patrimonio, en las aulas hemos de tener en cuenta que su tipología es enormemente amplia y diversa. Existe la posibilidad de recurrir, no ya a los grandes símbolos o elementos de referencia nacional, sino que podemos -debemos, desde su argumentación emocional- considerar el patrimonio local. Entendemos el patrimonio local en un sentido amplio, considerando para este tanto el conjunto de elementos que configuran el patrimonio existente en un espacio concreto -el municipio, la localidad-y que 
se encuentra "oficial" o generalmente reconocido por la colectividad, como el petit patrimoine, o patrimonio de proximidad, que incluye todos esos elementos propios del entorno del alumnado, y que tienen un simbolismo y un significado que lo conecta con un colectivo concreto, pero también con una cultura y un contexto histórico más amplios (BRETON, 2011). En este caso, la cercanía -en sentido espacial pero también cotidiano- y la accesibilidad para docentes y discentes a este tipo de "patrimonio menor" son un perfecto punto de partida para la indagación histórica (PLUCKROSE, 1993) y la obtención de respuestas formuladas por el alumnado desde su realidad e interés presente.

\section{UNA ÚLTIMA REFLEXIÓN: PERSPECTIVA PARA UNA ENSEÑANZA DE LA HISTORIA ÚTIL}

Analizadas las alternativas en las perspectivas patrimoniales para ser usadas en la enseñanza de la historia escolar, y sus consiguientes relaciones en los planos cognitivo y social, cabe retomar ahora el concepto de enseñar una historia útil y cuáles son los marcos que responden o no a esa utilidad.

Una reflexión acertada a este respecto debe partir del relativismo del concepto de utilidad, pues la utilidad dependerá, no solo del contexto espaciotemporal, sino también de los objetivos marcados para dicho contexto.

A lo largo de la descripción de las tres perspectivas patrimoniales definidas, hemos hecho referencia a la situación en la que, como mundo, nos encontramos: un mundo global -con lo que supone para los intercambios de personas, bienes y costumbres-, de tiempo líquido -un panorama de cambios continuos, difíciles, en ocasiones, de encajar- y formado por individuos que no pertenecen a un grupo, sino a una multiplicidad de ellos.

Con este panorama de fondo, los conceptos de nación, de identidad o de patrimonio revisten dificultad, aún más cuando los siglos previos han apostado por la construcción de identidades colectivas duras, bajo el paraguas de los estado-nación y la transmisión de la historia de la mano del concepto de verdad.

Los nuevos tiempos, incompatibles con esta tendencia, han modificado lo que venía siendo un continuo de sociedades y escuelas. Se ha producido un proceso de descarga de contenido político explícito en las narrativas maestras y 
las identidades colectivas se han descafeinado ante la realidad de la diversidad de los individuos.

Esta huida del patriotismo se ha traducido en una realidad de identidades de consumo, fruto de la transmisión de discursos sin significado para el receptor, que ofrecen un conocimiento histórico que no saben aplicar, que no utilizan para entender su identidad y que es, por lo tanto, insolvente; es decir, una identidad intuitiva (Gráfico 5).

Gráfico 5 - Realidad y alternativas para una historia útil

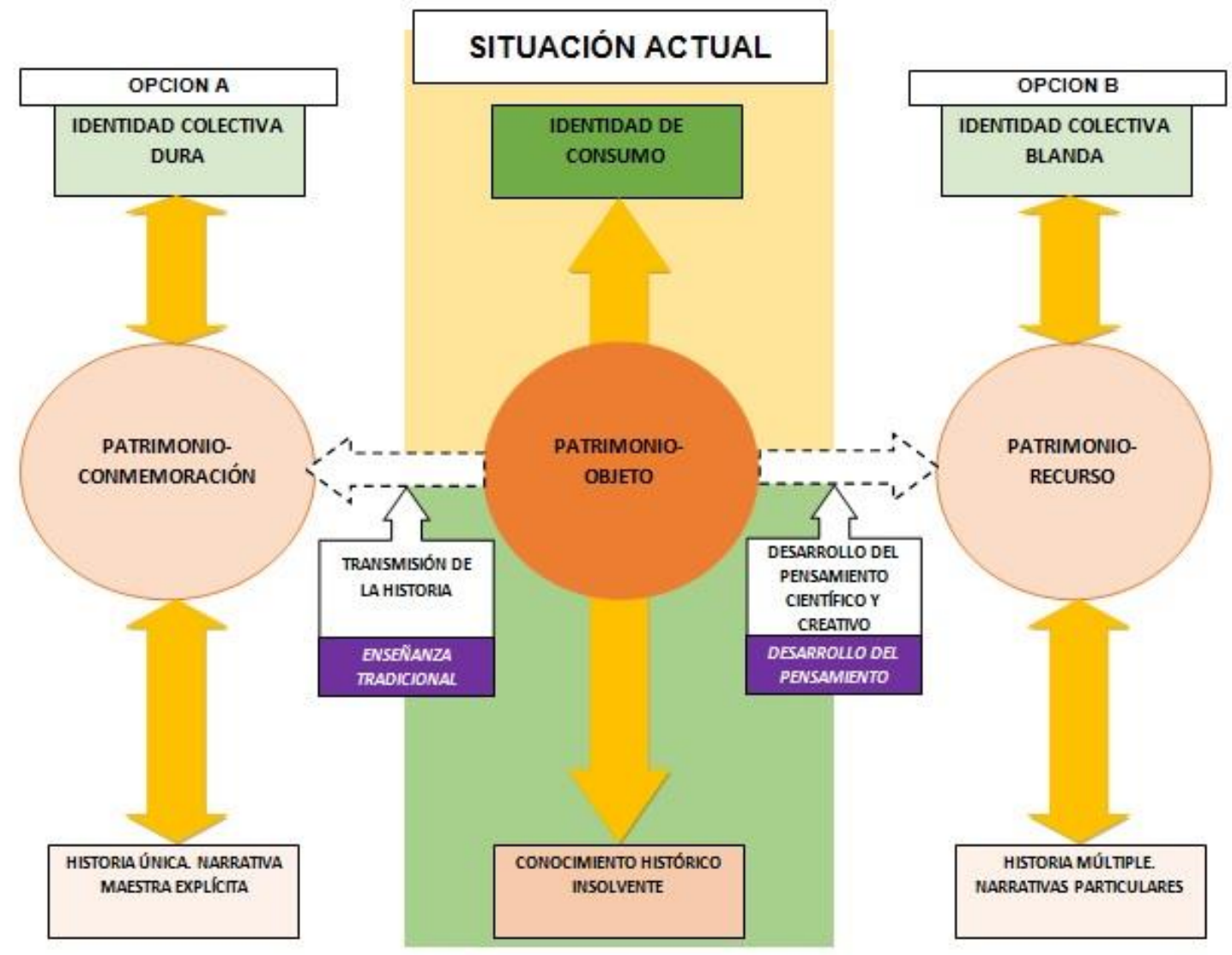

Fuente: elaboración propia, 2019.

Es un hecho que no ha existido una renovación metodológica adecuada a los tiempos; la causa puede estar, quizás, en que los objetivos de cambio no son lo suficientemente explícitos: sabemos de dónde venimos, pero no dónde queremos llegar, desde la propia relatividad del bien común.

En las aulas, el alumnado recibe un discurso que cuenta lo que pasó, sin dejar patente la apuesta por la identidad nacional y sin, por lo tanto, incluir un 
patrimonio ligado a esa identidad (en una perspectiva generalizada como desfasada). Sin embargo, lo que podría entenderse como una oportunidad para un nuevo planteamiento, se traduce en que el patrimonio actúa como una pieza más del discurso, complementaria e ilustrativa. Consecuentemente, el patrimonio es un patrimonio-objeto, argumentado de forma intuitiva -pues carecemos de discurso histórico suficiente-, que además sigue utilizándose poco en las aulas, a pesar de las perspectivas sobre su potencialidad (MOLINA; MUÑOZ, 2016).

La situación actual responde, entonces, entre las perspectivas patrimoniales definidas, a aquella en la que el sustento histórico es menor, mientras que la homogenización - disimulada con las libertades individuales-se hace progresivamente más patente. El ciudadano no tiene, pues, armas con las que argumentar cambio alguno pues, aunque forma parte de una masa, no acaba de identificarse con una colectividad a la que asociarse.

Este panorama de insolvencia histórica cuenta con dos situaciones alternativas para una historia escolar útil, dependiendo de para qué queramos enseñar historia: para formar miembros de una colectividad que utilicen su pasado como refuerzo de la identidad -en otras palabras, patriotas- o para formar ciudadanos críticos con el pasado, utilizándola para entender su presente diverso y propiciar un futuro de acuerdo a la realidad de los tiempos -en otras palabras, ciudadanos-. En ambos casos, la historia será útil de acuerdo con una finalidad y los mecanismos metodológicos (enseñanza transmisiva o desarrollo del pensamiento histórico), suficientemente conocidos para alcanzarla.

Lo que está claro es que estamos en el punto de decidir el sentido de la dirección bajo un marco que ha de ser necesariamente coherente. Pensándolo bien, la parcialidad y los descafeinados pueden originar situaciones menos idóneas que aquellas de las que huimos desde hace un tiempo. 


\section{Referencias}

ANGULO, Alfredo. Es que la historia ya no es como antes. DIKAIOSYNE, Mérida, v. 25, p. 163-176, 2010.

BARTON, Keith; LEVSTIK, LINDA. Teaching history for the common good. Oxford: Routledge, 2004.

BAUMAN, Zygmunt. Identidad. Madrid: Losada, 2003.

BRETON, Marie-Eve. Le patrimoine de proximité en contexte urbain comme nouvel espace d'identification collective: le cas de la Rue Saint-Malo à Brest. Université du Québec, 2011. Disponible en:

http://www.archipel.uqam.ca/4103/1/M12059.pdf. Acceso en: 28 abr. 2021.

BURKE, Peter. New perspectives on historical writing. Cambridge : Polity Press, 1993.

CALAF, Roser. Didáctica del patrimonio: epistemología, metodología y estudio de casos. Gijón: Trea, 2009.

CARRETERO, Mario. Voces y ecos en los programas y textos escolares. In: CARRETERO, Mario (ed.). Documentos de identidad: la construcción de la memoria histórica en un mundo global. Buenos Aires: Paidós, 2007, p. 75-85.

CISCAR, Josep; SANTIAGO, José Antonio; SOUTO, Xosé María. Identidades nacionales y territorialidad en los libros de texto: los estereotipos enciclopédicos en la geografía escolar. Scripta Nova: Revista electrónica de geografía y ciencias sociales, Barcelona, v.16, n. 418, 2011. Disponible en: http://www.ub.edu/geocrit/sn/sn-418/sn-418-36.htm. Acceso en: 28 abr. 2021.

CONSEJO DE EUROPA. Quality history education in the $21^{\text {st }}$ Century: principles and guidelines. Estrasburgo: Publications of Council of Europe, 2018.

CONWAY, Brian. Active remembering, selective forgetting, and collective identity: the case of Bloody Sunday. Identity: An International Journal of Theory and Research, [Filadelfia], v.3, n.4, p. 305-323, 2003. Disponible en: http://dx.doi.org/10.1207/S1532706XID0304_01. Acceso en: 28 abr. 2021.

CROUCH. David. Affect, heritage, feeling. In: WATERTON, Emma; WATSON, Steve (eds.). The palgrave handbook of contemporary heritage research. Nueva York: Palgrave MacMillan, 2015, p. 177-190.

CUENCA-LÓPEZ, José María; ESTEPA-GIMÉNEZ, Jesús; MARTíN, Myriam. Patrimonio, educación, identidad y ciudadanía: profesorado y libros de texto en la enseñanza obligatoria. Revista de Educación, [Madrid], v. 375, p. 136-159, 2017. 
EPSTEIN, Terrie. The effects of family/community and school discourses on children's and adolescents' interpretations of United States history.

International Journal of Historical Learning, Teaching and Research, [s.l.], v.6, n.1, p. 1-9, 2007. Disponible en: http://dx.doi.org/10.18546/HERJ.06.0.04. Acceso en: 28 abr. 2021.

ERCIKAN, Kadriye; SEIXAS, Peter. New directions in assessing historical thinking. Londres: Routledge, 2015.

FONTAL, Olaia. La educación patrimonial: teoría y práctica en el aula, el museo e internet. Gijón: Trea, 2003.

GATTI, Gabriel. Algunas anécdotas y un par de ideas para escapar de las ficciones modernas acerca de la identidad colectiva. Berceo, Logroño, v, 153, p. 13-56, 2007. Disponible en: https://doi.org/10.4000/eces.379. Acceso en: 28 abr. 2021.

GÓMEZ-REDONDO, Carmen; FONTAL, Olaia; IBÁÑEZ-ETXEBERRIA, Alex. Procesos de patrimonialización e identización patrimonial con uso de TIC en torno al arte contemporáneo. Artnodes: Revista de arte, ciencia y tecnología, Barcelona, v. 17, p. 52- 63, 2016. Disponible en: https://doi.org/10.7238/a.v0i17.2827. Acceso en: 28 abr. 2021.

GONZÁLEZ, Neus. L'ús didàctic i el valor educatiu del patrimonio cultural. 2006. Tesis (Doctorado en Didáctica de las Ciencias Sociales) - Universitat Autònoma de Barcelona, Barcelona, 2006.

HUTCHINS, Rachel. Nationalism and history education: curricula and textbooks in the United States and France. Londres: Routledge, 2015.

INNERARITY, Daniel. The democracy of knowledge. Nueva York: Bloombury Academic, 2013.

JASPER, James; MCGARRY, Aidan. Introduction: the identity dilemma, social movements, and contested identity. In: MCGARRY, Aidan; JASPER; James (eds.). The identity dilemma: social movements and collective identity. Philadelphia: Temple University Press, 2015. p. 1-17.

JENKINS, Keith. Repensar la historia. Madrid: Siglo XXI, 2009.

JODELET, Denise. Representaciones sociales: contribución a un saber sociocultural. In: JODELET. Denise; GUERRERO, Alfredo (coord.). Desvelando la cultura: estudios en representaciones sociales. Ciudad de Mexico: UNAMFacultad de Psicología, 2000. p. 7-30. 
LÓPEZ, Humberto; RODRÍGUEZ, Cecilia. El debate sobre identidad individual e identidad colectiva. Aportes desde la psicología social. MILLCAYAC, Revista Digital de Ciencias Sociales, Mendoza, v.1, n.1, p. 99-107, 2014. Disponible en: http://revistas.uncu.edu.ar/ojs/index.php/millca-digital/article/view/218. Acceso en: 28 abr. 2021.

LOWENTHAL, David. El pasado es un país extraño. Madrid: Akal, 1998.

LUCAS, Laura; DELGADO-ALGARRA, Emilio José. El profesor posmoderno de ciencias sociales: un modelo de buenas prácticas en educación patrimonial. REICE. Revista Iberoamericana sobre Calidad, Eficacia y Cambio en Educación, Madrid, v. 18, n. 1, p. 27-45, 2019.

MACDONALD, Sharon. Museums, national, postnational and transcultural identities. Museums and society, Leicester, v.1, n.1, p. 1-16, 2003. Disponible en: https://journals.le.ac.uk/ojs1/index.php/mas/article/view/3/50. Acceso en: 28 abr. 2021.

MACMILLAN, Margaret. Juegos peligrosos: usos y abusos de la historia. Barcelona: Ariel, 2010.

MARCUS, Alan; STOODAR, Jeremy; WOODWAR, Walter. Teaching history with museums. Nueva York: Routledge, 2012.

MARTíN, Myriam; CUENCA, José María. Educatio. Siglo XXI, Murcia, v.33, n.1, p. 3354, 2015. Disponible en: http://dx.doi.org/10.6018/j/222491. Acceso en: 28 abr. 2021.

MERCADO, Asael; HERNÁNDEZ, Alejandrina. El proceso de construcción de la identidad colectiva. Convergencia, Revista de Ciencias Sociales, Toluca de Lerdo, v. 53, p. 229-251, 2010.

MOLINA, María Mercedes. Nuevos enfoques disciplinares en el patrimonio cultural. El peligro de la mercantilización patrimonial. Revista ph, Sevilla, v. 91, p. 138-139, 2017. Disponible en: http://dx.doi.org/10.33349/2017.0.3871. Acceso en: 28 abr. 2021.

MOLINA, Sebastián; MUÑOZ, Rafael Emilio. La opinión del profesorado de educación secundaria sobre el papel del patrimonio en la enseñanza formal de las ciencias sociales: un estudio de caso. Revista Complutense de Educación, Madrid, v. 27, n. 2, p. 863-880, 2016.

https://doi.org/10.5209/rev_rced.2016.v27.n2.48411. Acceso en: 28 abr. 2021.

MORALES, Antonio José; CAURÍN, Carlos; SOUTO, Xosé Manuel. Percepción del mundo: mapas mentales y problemas socioambientales. Didáctica geográfica, Madrid, v. 14, p. 69-90, 2013. 
ORGANIZACIÓN PARA LA COOPERACIÓN Y EL DESARROLLO ECONÓMICO (OCDE). Trends Shaping Education 2019. París: OECD Publishing, 2019.

PÉREZ GARZÓN, Juan Sisinio. Poderes y deberes para la enseñanza de las ciencias sociales. In: LÓPEZ FACAL; Ramón (ed.). Ciencias sociales, educación y futuro: investigaciones en didáctica de las ciencias sociales. Santiago de Composterla: Universidad de Santiago de Compostela, 2016. p. 62-69.

PINTO, Helena. Usos del patrimonio en la didáctica de la historia: perspectivas de los alumnos y profesores portugueses relativas a la identidad y conciencia histórica. Educatio Siglo XXI, Murcia, v. 31, n.1, p. 61-88, 2013.

PINTO, Helena. Educação histórica e patrimonial: concepções de alunos e profesores sobre o passado em espaços do presente. Oporto: CITCEM, 2016.

PLUCKROSE, Henry. Enseñanza y aprendizaje de la Historia. Madrid: Morata, 1993.

PONCE, Ana Isabel. Teorías epistemológicas y conocimiento histórico del alumnado: diseño y validación de una prueba (Tesis doctoral). Universidad de Murcia, Universidade do Porto, 2019.

RACHIK, Hassan. Identidad dura e identidad blanda. Revista CIDOB d'Afers Internacionals, Barcelona, v. 73-74, p. 9-20, 2006. Disponible en: https://doi.org/40378. Acceso en: 28 abr. 2021.

RIEFF, David. Contra la memoria. Barcelona: Debate, 2012.

RODRÍGUEZ, Milagros Elena. La educación patrimonial transcompleja que emerge del patrimonio cultural-identidad- y ciudadanía. Revista Educación y Humanismo, Barranquilla, v. 21, n. 36, p. 101-120, 2019. Disponible en: https://doi.org/10.17081/eduhum.21.36.3074. Acceso en: 28 abr. 2021.

RÜSEN, Jörn. History: narration, interpretation and orientation. Nueva York: Berghahn books, 2008.

SCHUGERENSKY, Daniel. Adult citizenship education: an overview of the field. In: FENWICK; Tara; NESBIT; Tom; SPENCER, Bruce (eds.). Contexts of adult education: canadian perspectives. Toronto: Thompson Educational Publishing Inc., 2006. p. 68-80.

SCHUGERENSKY, Daniel. Educación ciudadana e identidad: la disputa por la comunidad imaginada. In: LÓPEZ FACAL, Ramón (ed.). Ciencias Sociales, educación y futuro: investigaciones en didáctica de las ciencias sociales. Santiago de Compostela: Universidad de Santiago de Compostela, 2016. p. 4861. 
SEIXAS, Peter; MORTON, Tom. The big six historical thinking concepts. Toronto: Nelson Education, 2013.

SOLÉ, Gloria. Educação histórica e educação patrimonial: desafios da investigação em Portugal. In: MIRALLES, Pedro; GÓMEZ, Cosme; RODRÍGUEZ, Raimundo (eds.). La enseñanza de la historia en el siglo XXI: desarrollo y evaluación de competencias históricas para una ciudadanía democrática. Murcia: EDITUM, 2017. p. 145-166.

SUBERO, David; ESTEBAN-GUITART, Moisés. Más allá del aprendizaje escolar: el rol de la subjetividad en el enfoque de los fondos de identidad. Teri, Salamanca, v. 23, n.1, p. 213-236, 2020. Disponible en: http://dx.doi.org/10.14201/teri.20955. Acceso en: 28 abr. 2021.

TAROZZI, Massimiliano; TORRES, Carlos Alberto. Global citizenship education and the crises of multiculturalism: comparative perspectives. Nueva York: Bloomsbury Publishing, 2016.

VAN BOXTEL, Carla; GREVER, Maria; KLEIN, Stephan. Heritage as a resource for enhancing and assessing historical thinking: Reflections from the Netherlands. In: ERCIKAN, Kadriye; SEIXAS, Peter (Eds.). New directions in assessing historical thinking. Londres: Routledge, 2015. p. 40-50.

VANSLEDRIGHT, Bruce. Narratives of Nation-State, historical knowledge and school history education. Review of Research in Education, [s.l.], v. 32, p. 109 146, 2008. Disponible en: http://dx.doi.org/10.3102/0091732X07311065. Acceso en: 28 abr. 2021.

VANSLEDRIGHT, Bruce. Assessing historical thinking and understanding. Innovative designs for new standards. Londres: Routledge, 2014.

WATERTON, Emma; WATSON, Steve. Heritage as a focus of research: Past, present and new directions. In: WATERTON, Emma; WATSON, Steve (eds.). The Palgrave handbook of contemporary heritage research. Nueva York: Palgrave MacMillan, 2015. p. 1-20.

Universidade do Estado de Santa Catarina - UDESC

Programa de Pós-Graduação em História - PPGH

Revista Tempo e Argumento

Volume 13 - Número 32 - Ano 2021 tempoeargumento@gmail.com 